
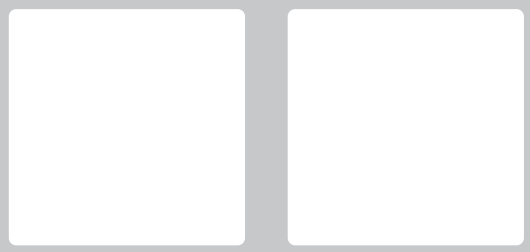

\title{
IMERSÃO SOCIAL E PROCESSOS INOVATIVOS: ESTUDO DO POLO CALÇADISTA DE NOVA SERRANA - MINAS GERAIS
}

\section{Embeddedness and Innovative Processes: a study of shoes cluster in Brazil}

\section{Cássio Murilo da Silva}

Mitre Consultoria Empresarial, PPGA - PUCMinas, email:

cassiomurilods@gmail.com

\section{Gláucia Maria Vasconcellos Valle}

PPGA-PUCMinas, email:galvale@terra.com.br

\section{Rodrigo Baroni de Carvalho}

Programa de Pós-Graduação em Administração- Pontifícia

Universidade Católica - PUCMinas, email: rodbaroni@yahoo.com.br

\section{RESUMO}

Recorrendo à abordagem das redes sociais, o presente artigo analisa os processos inovativos em dois diferentes tipos de empresas (empresas de alto e baixo desempenho inovativo), localizadas no Território Produtivo de Nova Serrana (MG). Utilizou-se o estudo de casos múltiplos, envolvendo duas empresas de cada categoria. Buscou-se, primeiramente, aferir o nível de inovação em produtos e processos e, em seguida, mapear as redes sociais e empresariais das empresas. Os resultados mostram que as redes das empresas de alto desempenho são mais densas e melhor integradas, apresentando maior frequência de laços fortes, o que faz com que recursos e informações trafegadas sejam de natureza mais refinada, com propagação abrangente e dinâmica. Por outro lado, as redes das empresas de baixo desempenho são mais porosas, caracterizadas por maior presença de atores isolados, ausência de atores centrais, sendo as informações e recursos que fluem em seu interior de natureza mais local.

Palavras-chave: Inovação. Redes sociais. Território produtivo

\section{ABSTRACT}

Based upon the perspective of social networks, this paper discusses the innovative processes in two different categories of companies (high performance enterprises; low performance enterprises), located in Nova Serrana shoes cluster, in Minas Gerais State, Brazil. The results show that the networks of companies described as high innovative performance have denser networks, many strong ties and few isolated actors, turning more refined the embedded information and resources and more dynamic their propagation and usage. On the other hand, the social networks of low innovative performance companies are more diffuse, with many isolated actors, absence of central actors, making more difficult the process of propagation and appropriation of novel information, especially from the outside world.

Keywords: Innovation. Social networks. Cluster. 


\section{INTRODUÇÃO}

Devido à necessidade de países e regiões de desenvolverem uma agenda de desenvolvimento e crescimento em seu parque industrial e pela crescente necessidade de gerar empregos e renda para suas populações, grande ênfase vem sendo atribuída aos estudos sobre inovação de produtos e processos na área acadêmica nas últimas décadas, sobretudo em aglomerações industriais com especialização da produção, conceituadas como Territórios Produtivos para os fins deste estudo.

No entanto, apesar de fartos, esses estudos mantiveram-se com foco, quase exclusivo, nos ganhos de externalidades tangíveis que permeiam os processos inovativos no interior desses territórios, tais como as regiões da Emília Romagna, Itália (AMATO NETO, 2000); Nova Serrana, Brasil (CROCCO, SANTOS, SIMÕES \& HORÁCIO, 2001; REZENDE, 2004; SUZIGAN, FURTADO, GARCIA \& SAMPAIO, 2005). A academia, sobretudo nos países em desenvolvimento, não vem dando uma atenção mais pronunciada em processos inovativos sob uma ótica sociológica, incluindo na discussão, de maneira mais incisiva, a base mais submersa que está na origem da inovação enquanto processo que se cria e se desenvolve na relação entre pessoas e empresas em seu contexto de vida real (MARTES et al., 2006, p. 13; RASERA \& BALBINOT, 2010, p. 135; LI, BATHELT \& WANG, 2011; HALINEN \& TORNROOS, 1998).

Apesar da relevância do tema das redes sociais em aglomerações produtivas, com literatura extensa em países mais desenvolvidos, Vasconcelos e Oliveira (2012) alegam que poucos estudos no Brasil têm abordado o assunto correlacionando redes empresariais e seus impactos em processos inovativos, dando ênfase ao mapeamento de redes e o posicionamento de seus atores como elos fundamentais na difusão de inovações no interior e exterior de redes empresariais (grifo nosso). Pesquisas realizadas por esses autores em sete periódicos nacionais e anais de dois congressos não encontraram trabalhos que focalizem especificamente a imersão social (relacional e estrutural) e seus impactos nos resultados empresariais - desempenho, aquisição de capacidades e inovação, por exemplo (VASCONCELOS e OLIVEIRA, 2012). Em recente revisão sistemática da literatura sobre a capacidade de inovação de clusters, Bittencourt, Galuk, Daniel e Zen (2018) analisaram as bases de dados EBSCO, SCOPUS e Web of Knowledge desde 2005 e encontraram 18 trabalhos sobre a temática, concluindo que enquanto a maioria dos estudos aborda a inovação em nível da firma, há escassez relativa de estudos que investigam as interações que acontecem nas aglomerações inter-organizacionais.

Territórios Produtivos apresentam-se como regiões privilegiadas para os estudos das interações produtivas, uma vez que a "indústria localizada" tem funções variadas de "preparar os avanços modernos em divisão do trabalho nas artes mecânicas e na tarefa da administração da empresa" (MARSHALL, 1982, p.232). Muller (2009) alega que um cluster é uma rede de empresas e instituições interligadas em um campo particular da indústria que está circunscrita em uma determinada área geográfica e que pertencendo a essa área, as empresas podem aumentar sua capacidade de inovação, beneficiando de externalidades positivas como o conhecimento que é gerado internamente ao arranjo, maiores acessos a recursos e tecnologias que são susceptíveis de ajudar as empresas a adquirir vantagens competitivas em relação aos concorrentes que não fazem parte dessa rede. Em survey recente com 47 empresas do polo têxtil de Ilhota (Santa Catarina), Mondini, Amal e Gomes (2016) identificaram que as externalidades, como o maior fluxo de clientes, acesso à mão de obra especializada e disponibilidade de fornecedores, são pouco aproveitadas e que potencializar as externalidades poderia melhorar o desempenho em inovação das empresas envolvidas.

Um importante impulso para uma visão do contexto das relações sociais e empresariais e sua gênese para os processos econômicos foi dada a partir do desenvolvimento dos argumentos dos laços sociais e do conceito de embeddedness, na década de 1970, por Granovetter $(1973,1976,1985,2005,2007)$ e a ampliação desses conceitos por Burt (1992), que demarcaram as possibilidades de análises dos processos inovativos, retirando a exclusividade de análises de cunho utilitarista da escola neo-clássica e abrindo novas frentes por meio da linha da economia sociológica.

Verifica-se, pelos estudos empreendidos, que as redes sociais e empresariais estão na base da estrutura econômica de muitas regiões, mesmo aquelas que não são bem-sucedidas e têm atraído pouca 
atenção, o que levou Castilla, Hwang, Granovetter e Granovetter (2000, p. 218) alegar que "o problema interessante não é se as redes são importantes em uma região, mas que tipos de redes estão associadas a que tipos de resultados". Schmidt e Zen (2019) enfatizam a relevância de estudos desta temática, pois consideram que a compreensão dos elementos que impulsionam ou limitam o desenvolvimento de clusters pode auxiliar políticas públicas futuras que visam o desenvolvimento de tais arranjos.

A correlação entre processos inovativos e redes empresariais no interior de espaços geográficos definidos, caracterizados pelo tipo horizontal de relacionamentos entre empresas da mesma cadeia produtiva, poderá se mostrar profícua, sobretudo no Brasil, onde grande parte das empresas ainda considera o processo inovativo endógeno à firma; apesar dessa percepção ter mudado nas últimas décadas, tendo em vista que a inovação de produtos e processos tem sido relacionada fortemente com o aumento do desempenho empresarial (PELLEGRIN, BALESTRO, ANTUNES JÚNIOR \& CAULLIRAUX, 2007).

Segundo Tomael, Alcará e Di Chiara (2005), é nesse contexto que se pode situar a importância das redes sociais e empresariais, pois elas dependem da interação de diversos atores - internos e externos à organização - dispostos a compartilhar informações e experiências, visando ao aprendizado organizacional e, consequentemente, contribuindo para a construção de novos conhecimentos, podendo, ainda, de maneira dinâmica propagar e sustentar processos inovativos tanto no interior das firmas, como replicação para empresas que pertencem ao território produtivo.

Utilizando de uma abordagem de estudo de casos múltiplos, o presente trabalho objetiva descrever como é o processo de trâmite de informações e recursos vitais para o desenvolvimento dos processos inovativos no interior das redes empresariais em duas categorias distintas de empresas: empresas de baixo e alto desempenho, sob a luz da inovação de processos e produtos. Tendo como questão norteadora "Como as redes de relacionamento presentes em Nova Serrana - MG propagam e sustentam processos inovativos em duas categorias distintas de empresas: empresas de alto desempenho inovativo e empresas de baixo desempenho inovativo", o artigo tem por objetivo analisar a dinâmica do processo inovativo em redes empresariais, tais como: configurações de redes mais aptas a transmitir e reter informações e recursos; importância de atores para além da rede imediata; relevância da densidade e transitividade para o trâmite de informações da rede. Para além da introdução, o artigo está organizado da seguinte forma: a seção 2 contempla o referencial teórico com os temas inovação, redes sociais e inovações em redes; a seção 3 detalha a metodologia de pesquisa e o contexto do território produtivo; na seção 4 são analisados os resultados e a seção 5 contém as conclusões.

\section{REFERENCIAL TEÓRICO}

\subsection{Inovação}

Para Schumpeter (1982), a teoria clássica está balizada pelo conceito de equilíbrio estático do sistema econômico, ou seja, somente após as ocorrências de mudanças disruptivas no interior do sistema, é que a avaliação pode ser efetuada. Ainda segundo Schumpeter (1982), essas mudanças são "novas combinações", ou "inovações", que lançam o sistema produtivo sempre a um novo equilíbrio, ou um novo plano de desenvolvimento. Essas mudanças se apresentam em cinco situações distintas: a) introdução de um novo bem; b) introdução de um novo método de produção; c) abertura de um novo mercado; d) conquista de uma nova fonte de matéria-prima ou de bens semimanufaturados; e) estabelecimento de uma nova organização de qualquer indústria.

Davila, Epstein e Shelton (2007) informam que os mecanismos que promovem as inovações de produtos e processos nas organizações precisam ser acompanhados de perto pela gerência executiva e citam sete passos que podem ser seguidos para que o processo seja otimizado: a) exercer sólida liderança sobre os rumos e as decisões sobre inovação; b) integrar a inovação à mentalidade do negócio; c) alinhar a inovação à estratégia da empresa; d) administrar a tensão natural entre criatividade e captação de valor; e) neutralizar anticorpos organizacionais; f) cultivar uma rede de inovação além dos limites da organização (grifo nosso); e g) criar indicadores de desempenho e as recompensas adequadas. 
O ponto de confluência entre a inovação, enquanto conceito estanque, e as redes sociais e empresariais, imprimindo um argumento mais interativo no desenvolvimento dos processos inovativos, vem sendo destacado por vários autores (GOLLO, 2006; BRITTO, STALLIVIERI, CAMPOS \& VARGAS, 2007; LUNDVALL \& NIELSEN, 2007; ROBERTSON et al.; 2012). A abordagem da inovação aberta de Chesbrough (2003) estabelece ideias e caminhos externos ao mercado no mesmo nível de importância que aquele reservado a ideias e caminhos internos ao mercado durante a era da inovação fechada (CHESBROUGH, 2003). Os argumentos desenvolvidos por Chesbrough (2003) abrem possibilidades para uma transição conceitual mais tênue das correntes investigativas sobre inovação e rede social, e também para uma maior amplitude da inovação em redes de relacionamentos, apresentando, portanto, os Territórios Produtivos como objetos preferenciais para os estudos das interações entre esses dois conceitos fundamentais.

\subsection{Redes Sociais}

A Análise de Redes Sociais (ARS), sobretudo nos estudos organizacionais, vem ampliando seu campo de atuação nos últimos anos com trabalhos que enfatizam aspectos relacionados ao desenvolvimento das estruturas das redes como estratégia de evolução e posicionamentos competitivos. Apesar dos estudos sobre redes sociais ter em Georg Simmel, no início do século XX, uma referência sobre a visão da sociedade composta por uma intricada rede de múltiplas relações (TEDESCO, 2007), foi somente a partir dos trabalhos de Granovetter (1973, 1976, 1985, $2005,2007)$ que os impactos dessas relações na vida econômica tiveram seu ponto de abrangência com o desenvolvimento dos argumentos dos laços sociais e embeddedness, ou imersão social.

Rede social é definida como um conjunto de nós ou atores (pessoas ou organizações) ligados por relações sociais ou laços, enraizados nas estruturas sociais, sendo que os laços entre os atores têm força e conteúdo; mas rede social é, sobretudo, uma metáfora do sistema de interdependências que é definida metodologicamente e por razões técnicas e, que traz em si um conjunto de relações específicas (colaboração, apoio, aconselhamento, controle ou influência) entre um conjunto finito de atores (CASTILLA et al., 2000; LAZEGA \& HIGGINS, 2014).

Para Li, Bathelt \& Wang (2011), Vale $(2006,2007)$ e Vale e Castro (2010), redes são relações sociais (e econômicas) contextualizadas de agentes e empresas que contêm elementos de reciprocidade, visão tecnológica consistente e uma visão de natureza contínua das relações que envolvem práticas, tais como resolução de problemas conjuntos ou troca de informações, que vão além de uma relação de troca baseada puramente em preço. Para esses autores, redes sociais contextualizadas ajudam a explicar e compreender as transformações mais profundas em clusters.

A análise de redes sociais tem demonstrado considerável poder analítico e acumulam-se evidências de que a ação humana é afetada pelas relações sociais em que os agentes estão imersos, sendo a participação em redes fator importante na ampliação da capacitação acerca das tendências de tecnologias e mercados e de seus impactos na sociedade e no meio ambiente (CANONGIA, SANTOS, SANTOS \& ZACKIEWICK, 2004; MIZRUCHI, 2006).

Redes sociais são formadas por laços, que podem ser fortes ou fracos. Laços fortes envolvem compromissos de tempo mais longos, tráfego de informações e recursos de natureza mais refinada, e também criam maior coesão social no interior de redes. Laços fortes apresentam duas vantagens primárias: a) são associados com informações de alta qualidade e conhecimento tácito; b) servem como mecanismos de controle para governar comportamentos entre as partes (GRANOVETTER, 1973; ROWLEY, BEHRENS \& KRACKHARDT, 2000).

Laços fracos ligam atores fora de seu círculo mais íntimo e são caracterizados pelos relacionamentos pouco frequentes, formados em ocasiões nos quais os contatos são fortuitos ou de curta duração. São canais preferenciais na difusão de informações e podem desempenhar a função de pontes que ligam redes distantes. Laços fracos são mais propensos do que fortes para desempenhar o papel de transmissão de informações únicas e não redundantes (GRANOVETTER, 1973).

Desenvolvendo análises estruturais e de concorrência, Burt (1992) amplia os conceitos dos estudos sobre redes sociais e alega que o aumento da rede sem considerar sua diversidade pode paralisá-la. Para 
este autor, o que importa é o número de contatos não-redundantes no interior de uma rede de relacionamento. Os benefícios de informações numa rede de relacionamento, segundo Burt (1992), ocorrem de três formas: a) acesso - receber uma informação e saber que poderá usá-la, apesar de serem informações imprecisas e muitas vezes fora de foco; $b$ ) sincronismo - contatos pessoais podem informar ao ator mais cedo do que outros participantes da rede sobre uma nova informação recebida pela rede; c) referências - que são os atores que se conhecem na rede e que poderão executar certo tipo de trabalho.

Trabalhando sobre os argumentos de redes densas, onde há prevalência de laços fortes e redes difusas, sendo que a predominância recai, sobretudo, sobre os laços fracos, Burt (1992) faz uma correlação sobre custo de oportunidades. Segundo o mesmo, redes densas são mais ineficientes, pois retornam menos informações e recursos de natureza nova, que redes difusas. A solução é colocar mais tempo e energia em adicionar contatos não redundantes para rede densa. Ao contrário, redes difusas oferecem oportunidades de informações não redundantes devido aos laços entre os atores serem mais fracos e assim propiciarem informações de fora da rede social imediata.

Ao salientar os contatos não redundantes entre os atores de uma rede, Burt (1992) forja o conceito de buraco estrutural. Contatos não redundantes apresentam falhas nos contatos entre eles [...] está falha é direta, simplesmente não existe nenhum contato direto entre os atores, ou uma das partes tem contatos que exclui o outro (MACIEL \& CASTRO, 2010, p. 77), e as condições empíricas que indicam um buraco estrutural são de Coesão e Equivalência Estrutural. Fortes relacionamentos indicam a ausência de buracos estruturais, tais como relacionamentos entre pai e filho, irmão e irmã, marido e mulher; esses apresentam, portanto, uma maior coesão. Quanto à equivalência estrutural, são relacionamentos que apresentam os mesmos contatos, levando às mesmas fontes de informações, sendo assim redundantes.

Burt (1992) aponta que para uma rede ser otimizada precisa de dois princípios básicos: eficiência e eficácia. Eficiência diz respeito a aumentar o número de contatos não redundantes para maximizar a eficiência dos buracos estruturais. E eficácia "requer distinguir contatos primários de secundários e focar recursos na preservação de contatos primários". "Contatos, aqui, não são pessoas do outro lado de suas relações, eles são portas de contatos aos agrupamentos de pessoas além" (BURT, 1992, p. 69).

Com o argumento de embeddedness ou imersão, Granovetter (1985) aponta que a vida social está imbricada na vida econômica e vice-versa, e que os comportamentos e as instituições ao serem analisadas são tão compelidos pelas contínuas relações sociais que interpretá-los como sendo elementos independentes representa um grave erro. Granovetter (1985, 2005,2007 ) divide a ação econômica para busca de satisfação das necessidades em duas perspectivas distintas: subsocializada e a supersocializada. Na perspectiva subsocializada - base da economia clássica e neo-clássica, no qual a ação humana está atomizada na ação utilitarista, todos os impactos da estrutura social sobre a produção, a distribuição e consumo são rejeitados, com o sistema de preços contendo todas as informações necessárias para a realização das trocas econômicas.

Na perspectiva supersocializada - o indivíduo está imerso, dentro de uma moral generalizada, na qual os padrões comportamentais são interiorizados e, portanto, onde as relações sociais existentes exercem efeitos periféricos sobre os comportamentos (GRANOVETTER, 1985, 2005, 2007).

Granovetter $(1985,2005,2007)$ conclui que seres humanos não desenvolvem relações como uma busca frequente de maximização utilitarista (subsocializa$d a$ ), e por outro lado, os padrões comportamentais não estão interiorizados a priori (supersocializado). Os atores não se comportam nem tomam decisões como átomos fora de um contexto social, e nem adotam de forma servil um roteiro escrito para eles pela intersecção específica de categorias sociais que eles porventura ocupem; em vez disso, suas tentativas de realizar ações com propósito, estão imersas em sistemas concretos e contínuos de relações sociais (GRANOVETTER, 1985, 2005, 2007).

De acordo com essa lógica, o argumento de embeddedness ou imersão social se torna a questão central na pesquisa de redes sociais. Redes de negócios são estruturas de relações de troca entre os atores de negócios, empresas, bem como indivíduos - estruturas que emergem, evoluem e se dissolvem com o tempo em um processo contínuo e interativo 
(Halinen \& Tornroos, 1998). As redes de relacionamentos sociais ou empresariais envolvem dimensões estruturais e relacionais. Na dimensão estrutural, os atores trocam bens e serviços, transferem recursos e informações. Na estrutura, estão presentes relações de poder, confiança e oportunismo, controle social, sistemas de alimentos de interesses, formas de negociação e as formas de seleção de fornecedores (SACOMANO \& TRUZZI, 2004). Para Capioto, Barbosa, Kurumoto e Cotrim (2019), os estudos sobre a dimensão estrutural da imersão social privilegiam o impacto da densidade e da posição da rede no desempenho das atividades corporativas, ao passo que os trabalhos sobre a dimensão relacional da imersão social enfatizam a coesão das relações entre os atores e a frequência dos relacionamentos.

Por sua vez, a dimensão relacional diz respeito às interações entre dois atores, conceituados especificamente pelas relações entre laços fortes e fracos (GRANOVETTER, 1973, 1976), representadas como uma combinação de quantidade de tempo, a intensidade emocional, a intimidade (confiança mútua), e os serviços recíprocos que caracterizam a amarra (ROWLEY, BEHRENS \& KRACKHARDT, 2000). A conjunção das análises desses conceitos correlacionados permite uma visualização dinâmica da localização dos atores numa determinada rede, o que possibilita inferir que tipo de informação passa por ele, e qual sua participação na distribuição, ou não, dessa informação para outros atores daquela determinada rede ou redes além.

\subsection{Inovação em Redes}

A visão da inovação como algo restrito e internalizado em hierarquias sofre mudanças radicais, saindo de um conceito de investimentos exclusivos em P\&D (Pesquisa \& Desenvolvimento) para uma visão mais relacional. Uma implicação importante dessa nova abordagem é que qualquer análise de inovação e produção de conhecimento ao nível da empresa deve levar em conta o posicionamento da rede da empresa e o grau em que a empresa pode contar com competências de fora (LUNDVALL \& NIELSEN, 2007).

A rede de relacionamentos serve como lócus de inovação porque fornece acesso em tempo útil para o conhecimento e os recursos que de outra forma não estariam disponíveis, ao mesmo tempo que testa conhecimentos, aprendizagem e capacidades internas. Neste sentido, pode-se afirmar que nas redes sociais e empresariais, a inovação decorre da capacidade de promover a troca e a utilização de informações de maneira muito mais intensa do que em qualquer outro lugar (POWELL, KOPUT \& SMITH-DOER, 1996; PELLEGRIN et al., 2007).

Balestrin e Verschoore (2008) alegam que as empresas não perderam a sua identidade legal, mas abriram as suas portas para contínuos aprimoramentos externos interdependentes, com diversos parceiros na sua cadeia produtiva, e que os contemporâneos padrões de competitividade exigem, portanto, que as empresas busquem estratégias competitivas e cooperativas simultaneamente. Em mercados competitivos, a existência de uma estratégia bem definida de inovação se faz ainda mais necessária, conforme destacado por Melo Filho, Gonçalves, Cheng e Muniz (2015) que atestaram como a utilização da ferramenta de planejamento estratégico de roadmapping contribuiu para a geração de diretrizes de inovação para um conjunto de firmas localizadas em um conglomerado industrial metal-mecânico do estado de Minas Gerais. No contexto deste trabalho, havia uma demanda premente de redirecionar as firmas para atenderem um novo setor-cliente com maiores exigências tecnológicas que os setores-clientes usuais.

Sobre a importância das redes de relacionamentos empresariais no processo de inovação, o trabalho de Ahuja (2000) demonstrou que as relações diretas entre os atores em uma rede afetam positivamente $o$ resultado da inovação, por fornecer três substantivos benefícios: a) partilha de conhecimentos; b) pela facilidade de reunir competências complementares diferentes; e c) efeito positivo de vínculos diretos que emergem através de economias de escala em pesquisas, que surgem quanto projetos maiores geram muito mais conhecimento que projetos menores. A Figura 1 foi elaborada pelos autores e demonstra o modelo teórico proposto para a pesquisa empírica. A seta pontilhada aponta o fluxo de informações e recursos, que pela configuração específica da rede empresarial, pode ser captada ou não para fomentar processos inovativos. 
Figura 1 Representação teórica da propagação e sustentação de processos inovativos através das redes empresariais

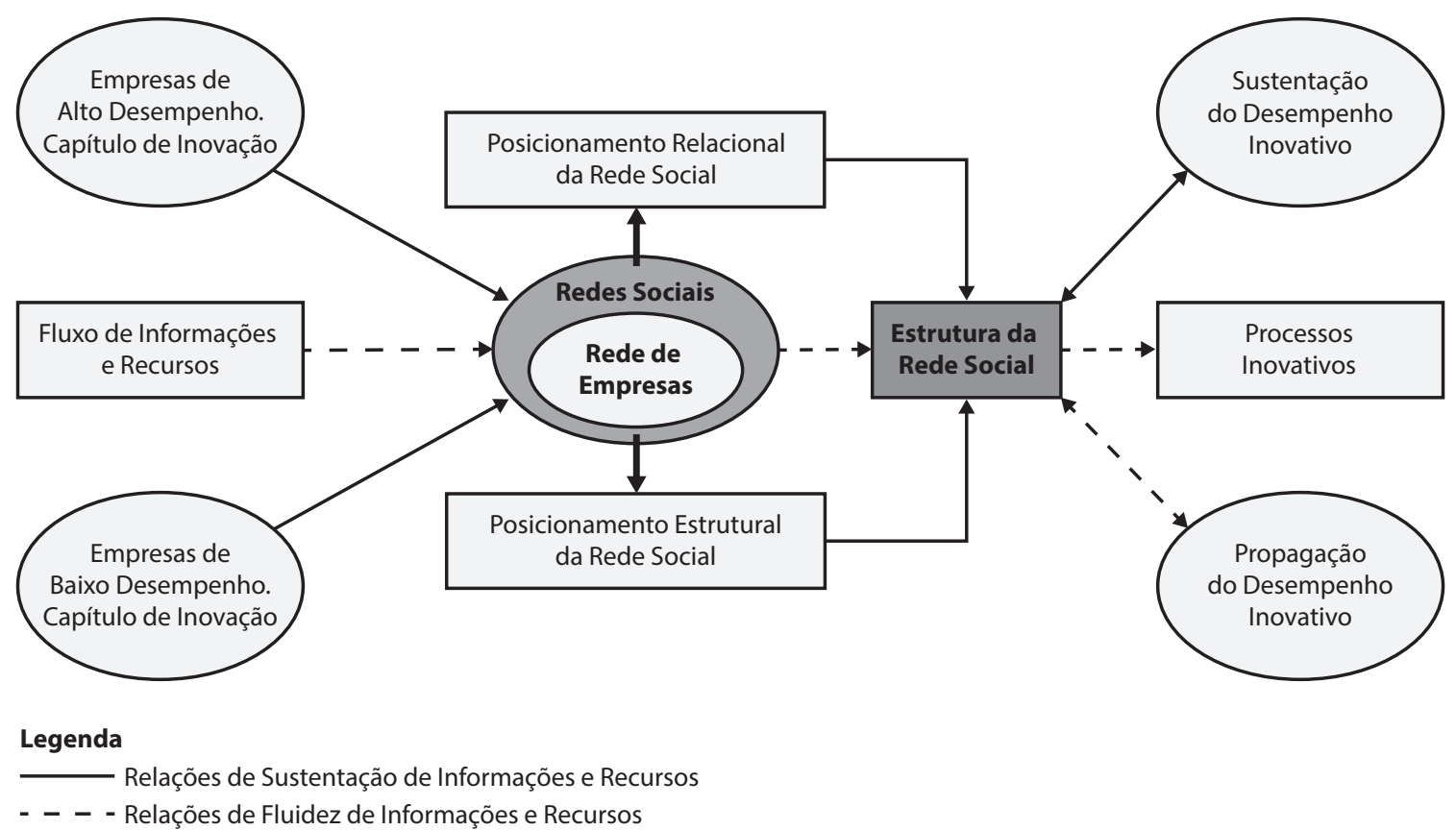

Fonte: Elaborado pelos autores.

Na Figura 1, a diferenciação de empresas de alto e baixo desempenho inovativo é lastreada na síntese de critérios propostos por Tidd, Bessant e Pavitt (2008); Carreteiro (2009); Robertsson, Casali e Jacobson (2012), que são detalhados na seção seguinte sobre a metodologia de pesquisa. Por sua vez, os elementos posicionamento relacional e posicionamento estrutural da rede social são baseados no trabalho de Sacomato Neto e Truzzi (2004). A terminologia de sustentação e propagação de desempenho inovativo no contexto de redes sociais é coerente com a perspectiva encontrada em Tomael, Alcará e Di Chiara (2005).

\section{METODOLOGIA DE PESQUISA}

\subsection{Procedimentos Metodológicos}

A pesquisa empírica foi efetuada com uma abordagem qualitativa de caráter descritivo em estudo de casos múltiplos. Foram selecionadas quatro empresas da base do Sindicato Intermunicipal da Indústria do Calçado de Nova Serrana-MG (SINDINOVA) que hoje possui 380 empresas sindicalizadas. Conforme Lazega e Higgins (2014), para que os reagrupamentos e reduções operados pela análise de rede tenham sentido e para que a validade externa dos resultados seja claramente estabelecida, os atores envolvidos em uma relação devem pertencer a uma mesma 'categoria'.

Outro fator importante é capacidade do estudo de caso em gerar explicação contextualizada, o que se torna ponto central neste estudo devido ao objeto pesquisado (GIL, 2008; YIN, 2010; MEYER, 2001; LEONARD-BARTON, 1990). A difusão de informações e recursos através das redes sociais e empresariais são fenômenos pouco estudados, portanto indicados para entender o contexto onde eles ocorrem, sendo importante a escolha de casos extremos, em que os tipos de situações polares tornam o processo de interesse transparente e observável (YIN, 2010; EISENHARDT, 1989).

A coleta de evidências para a pesquisa foi realizada em duas etapas distintas ilustradas na Figura 2. Na primeira etapa, consultaram-se fontes secundárias tais como pesquisas documentais no próprio Sindicato das Empresas e em órgãos que medem índices de evolução das empresas do território produtivo, sites das empresas, fontes oficiais do Ministério da Indústria e Comércio, evidências em participações em feiras. Está etapa compreendeu o período de 03/03/2015 a 03/06/2015. Na segunda etapa, realizaram-se as entrevistas focadas (YIN, 2010) para medir o nível 
Figura 2 Esquema teórico para estratégia de coleta de dados.

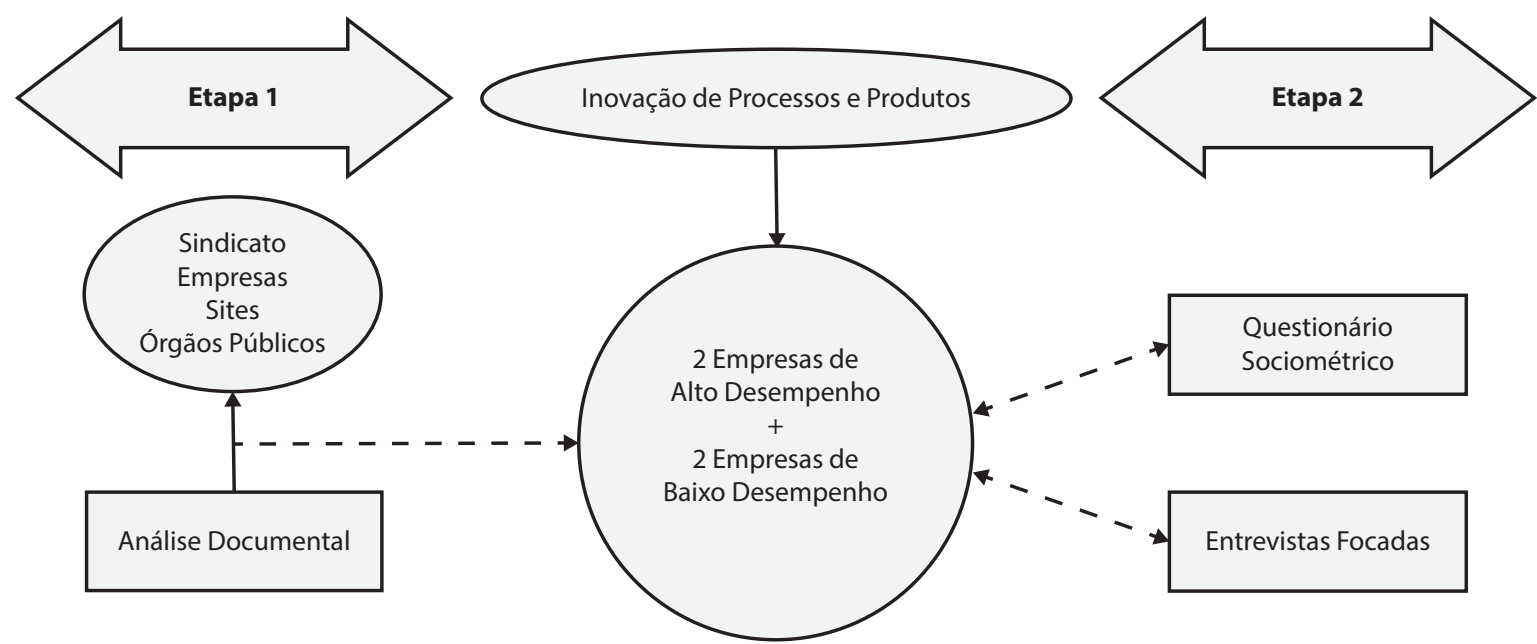

Fonte Elaborado pelos autores.

de inovação em produtos e processos das empresas selecionadas e foram mapeadas suas redes sociais e empresariais. Esta fase iniciou-se em 03/06/2015 e teve seu término em 30/09/2015.

\subsection{Critérios para escolha do Polo Calçadista de Nova Serrana - MG e das empresas do Polo}

Nova Serrana, em Minas Gerais, atualmente tem uma população de 84.550 habitantes e Produto Interno Bruto (PIB) de R \$ 596.029 Milhões (Instituto Brasileiro de Geografia e Estatística [IBGE], 2010). É conhecida como a capital nacional do tênis esportivo com 1.200 empresas no setor, perfazendo 20.176 empregos diretos (LEMOS, 2009), sendo que 56,49\% de toda a força de trabalho da cidade está empregada nesta indústria (IBGE, 2010), não havendo, no entanto, a existência de uma empresa âncora.

A grande parte da produção de calçados fabricados em Nova Serrana se dirige às classes C e D (CROCCO et al., 2001; RESENDE, 2004), o que demonstra o baixo valor agregado da produção, pois essas classes são mais sensíveis a preço. Santos (2009) alega que o futuro das empresas de Nova Serrana no mercado dependerá da busca de soluções relativas aos seguintes itens: a) melhoria da qualidade do produto; b) qualificação da mão-de-obra; c) desenvolvimento de novas linhas de produtos; d) expansão da capacidade produtiva; (d) inserção de novos processos de produção; e) investimento em design; (f) investimentos em novos métodos gerenciais; g) adoção de estratégias de marketing e principalmente; h) investimento em pesquisa e desenvolvimento.

Resende (2004) alega que a capacidade das empresas do cluster, no longo prazo, estará seriamente ameaçada enquanto as mesmas demonstrarem posição de vulnerabilidade frente às oscilações econômicas. O autor aponta as seguintes questões que contribuem para tal quadro: a) distância dos fornecedores de matérias-primas e de equipamentos; b) falta de incremento por parte das firmas na produção de calçados de couro; c) extrema dependência de intermediários e, d) impossibilidade de ações de marketing mais eficientes. Nova Serrana (MG) foi considerada ideal para a realização do estudo, tendo em vista sua dificuldade de apresentar inovações de produtos e processos, conforme o quadro apresentado pelos estudos consultados acima.

O Quadro 1 demonstra os critérios para seleção das empresas dos dois grupos focais. Optou-se por um período de análise de 05 (cinco) anos, para excluir surtos inovativos que não lograram êxito no longo prazo. 
Quadro 1 Critérios de seleção de empresas com base no desempenho inovativo

\begin{tabular}{|c|c|}
\hline ALTO DESEMPENHO INOVATIVO & BAIXO DESEMPENHO INOVATIVO \\
\hline PRODUTOS & PRODUTOS \\
\hline $\begin{array}{l}\text { Melhores performances em incremento de faturamento bruto sobre } \\
\text { vendas de novos produtos nos últimos } 5 \text { anos. }\end{array}$ & $\begin{array}{l}\text { Baixa performance em faturamento bruto sobre novos produtos nos } \\
\text { últimos } 5 \text { anos. }\end{array}$ \\
\hline $\begin{array}{l}\text { Maior frequência de lançamentos de novos produtos nos últimos } \\
5 \text { anos. }\end{array}$ & $\begin{array}{l}\text { Baixa frequência de lançamentos de novos produtos nos últimos } \\
5 \text { anos. }\end{array}$ \\
\hline Empresas que exportaram produtos nos últimos 5 anos. & Empresas que não exportaram produtos nos últimos 5 anos. \\
\hline $\begin{array}{l}\text { Melhores índices de produtividade por funcionário nos últimos } \\
5 \text { anos. }\end{array}$ & Baixos índices de produtividade por funcionário nos últimos 5 anos. \\
\hline PROCESSOS & PROCESSOS \\
\hline $\begin{array}{l}\text { Melhorias nos processos de fabricação que levaram a redução de } \\
\text { custos de fabricação nos últimos } 5 \text { anos. }\end{array}$ & $\begin{array}{l}\text { Baixo desempenho nos processos de fabricação e que levaram ao } \\
\text { aumento nos custos de fabricação nos últimos } 5 \text { anos. }\end{array}$ \\
\hline $\begin{array}{l}\text { Os melhores índices de avaliação pelos clientes (índice de satisfação) } \\
\text { nos últimos } 5 \text { anos. }\end{array}$ & $\begin{array}{l}\text { Baixos índices de avaliação pelos clientes (índice de satisfação) nos } \\
\text { últimos } 5 \text { anos. }\end{array}$ \\
\hline Alto desempenho em faturamento bruto nos últimos 5 anos. & Baixo desempenho em faturamento bruto nos últimos 5 anos. \\
\hline $\begin{array}{l}\text { Melhorias em outros processos, tais como: qualidade dos produtos } \\
\text { vendidos, se a empresa possui equipes de solução de problemas, } \\
\text { melhorias de produtividade pela incorporação de novos equipa- } \\
\text { mentos ou manutenção de equipamentos obsoletos como trocas de } \\
\text { peças; novas ideias de funcionários, clientes, ou fornecedores que são } \\
\text { colocados em prática e geram resultados satisfatórios e facilitaram a } \\
\text { inovação nos últimos } 5 \text { anos. }\end{array}$ & $\begin{array}{l}\text { Empresas que apresentaram baixo desempenho em outros processos, } \\
\text { tais como: qualidade dos produtos vendidos, se a empresa não possui } \\
\text { equipes de solução de problemas, não apresentou melhora de produ- } \\
\text { tividade pela incorporação de novos equipamentos ou manutenção } \\
\text { de equipamentos obsoletos como trocas de peças; não aproveitou } \\
\text { novas ideias de funcionários, clientes, ou fornecedores que geraram } \\
\text { resultados satisfatórios e que facilitaram a inovação nos últimos } 5 \text { anos. }\end{array}$ \\
\hline
\end{tabular}

Fonte Adaptado pelos autores a partir da síntese de critérios propostos por Tidd, Bessant e Pavitt (2008); Carreteiro (2009); Robertsson, Casali e Jacobson (2012).

Quadro 2 Medidas estruturais e relacionais

\begin{tabular}{c|l|l}
\hline MEDIDAS RELACIONAIS & \multicolumn{1}{|c|}{ CONCEITO } & \multicolumn{1}{c}{ AUTORES } \\
\hline Centralidade de Grau & $\begin{array}{l}\text { O ator que ocupa a posição central em uma Rede é aquele que } \\
\text { possuiu o maior número de conexões diretas. }\end{array}$ & $\begin{array}{l}\text { Lazega e Higgins (2014) } \\
\text { Lemieux e Ouimet (2012) }\end{array}$ \\
\hline Coesão Social & $\begin{array}{l}\text { A coesão social mede a intensidade dos pares de atores no interior } \\
\text { de uma rede social, sobretudo, as relações entre laços fortes e } \\
\text { fracos. }\end{array}$ & $\begin{array}{l}\text { Burt (1992) } \\
\text { Fialho (2014) } \\
\text { Sacomano Neto (2004) }\end{array}$ \\
\hline Proximidade & $\begin{array}{l}\text { Mede o grau de proximidade de um ator em relação a outros } \\
\text { atores na rede. }\end{array}$ & Lazega e Higgins (2014) \\
\hline $\begin{array}{c}\text { Centralidade de } \\
\text { Informação }\end{array}$ & $\begin{array}{l}\text { Situa o ator que detem o melhor caminho (não o menor) na rede, } \\
\text { onde a informação possa fluir. }\end{array}$ & $\begin{array}{l}\text { Tomaél e Marteleto (2006) } \\
\text { Gomes, Gonzalez-Arangüena, Manuel, } \\
\text { Owen, Pozo e Tejada (2003) }\end{array}$ \\
\hline MEDIDAS ESTRUTURAIS & \multicolumn{1}{c|}{ ConCEITO } & AUTORES \\
\hline Densidade & $\begin{array}{l}\text { É proporção de laços efetivos entre laços possíveis. Uma medida do } \\
\text { grau de inserção dos atores na rede. }\end{array}$ & $\begin{array}{l}\text { Lazega e Higgins (2014) } \\
\text { Sacomano Neto e Truzzi (2009) }\end{array}$ \\
\hline Transitividade & $\begin{array}{l}\text { Indica a facilidade da rede social em fazer a conexão de três atores, } \\
\text { ou seja, se um nó A estiver ligado a um nó B e o nó B estiver ligado } \\
\text { a um nó C, então a probabilidade de A estar ligado a C é alta. }\end{array}$ & $\begin{array}{l}\text { Wasserman e Faust (1994) } \\
\text { Braga e Fazito (2011) }\end{array}$ \\
\hline
\end{tabular}

Fonte os autores 
A seção seguinte detalha as medidas relacionais e estruturais utilizadas na pesquisa bem como apresenta de maneira gráfica as fases da pesquisa.

\subsection{Esquema Teórico da Análise dos Dados}

No âmbito dos conceitos de imersão relacional e imersão estrutural preconizados por Granovetter (1973), Rowley et al. (2000), Sacomano Neto e Truzzi (2004) e Burt (1992), as redes sociais apresentam estruturas que permitem verificar o posicionamento do ator e como as informações e recursos transitam no interior dessas estruturas. A delimitação dessas redes sociais consiste nos pontos de vista pessoais de seres humanos e da maneira como eles percebem os negócios.

Após o mapeamento das redes sociais e empresariais dos egos (proprietários das empresas selecionadas) e a realização dos cálculos das medidas estruturais e relacionais de rede pelo software UCINET versão 6.587, que, segundo Everett e Borgatti (2001), é o software de rede mais popular existente no mercado, foram realizadas análises comparativas entre as duas categorias de empresas pesquisadas. $\mathrm{O}$ Quadro 2 apresenta as medidas utilizadas na realização desse estudo.

$\mathrm{O}$ esquema teórico da Figura 3 apresenta as fases de análises empreendidas, após a seleção de 04 (quatro) empresas, com dois grupos focais distintos.

Figura 3 Esquema teórico de análise dos casos múltiplos.

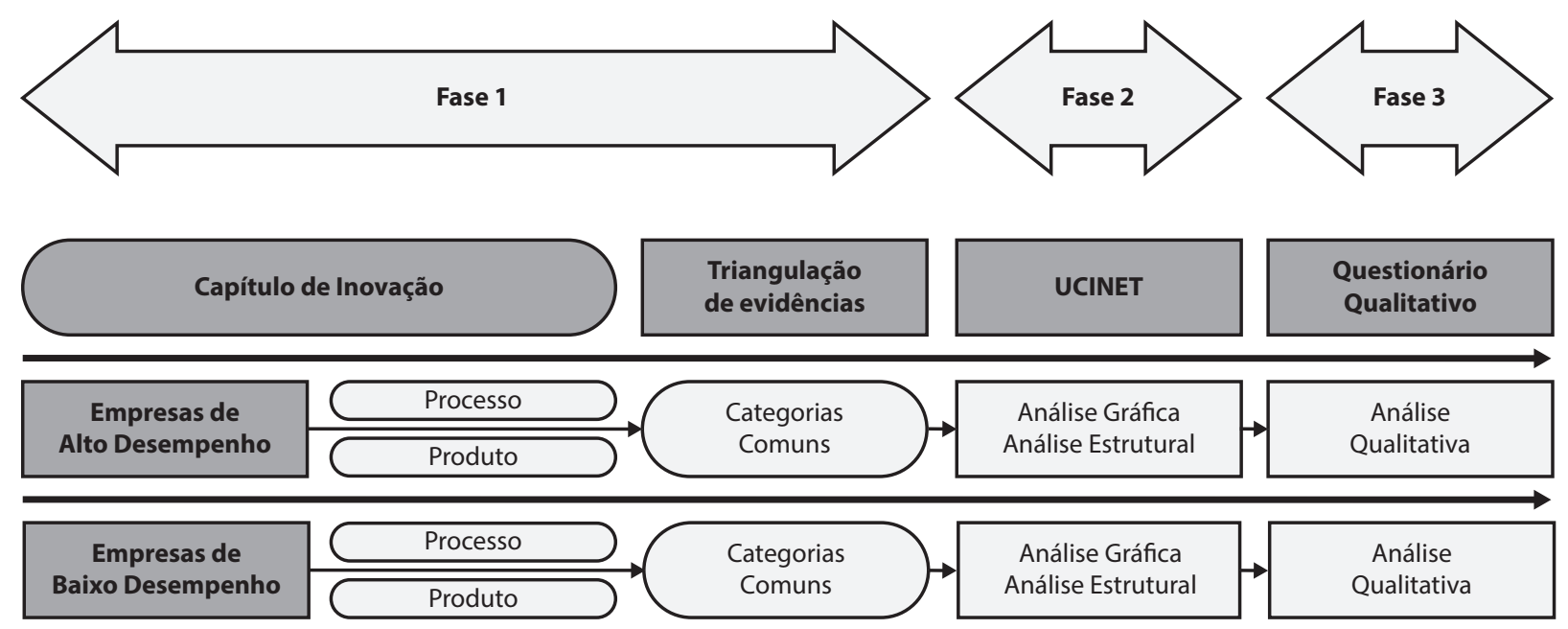

Fonte Elaborado pelos autores.

Quadro 3 Análise descritiva das indústrias selecionados

\begin{tabular}{l|c|c|c|c}
\hline & \multicolumn{2}{|c|}{ Empresas de Alto Desempenho Inovativo } & \multicolumn{2}{c}{ Empresas de Baixo Desempenho Inovativo } \\
\hline Perfil & L Calçados & D Calçados & P Calçados & S Calçados \\
\hline Data de Fundação & 1996 & 2012 & 1988 & 1998 \\
\hline Número Funcionários & 203 & 20 & 75 & 35 \\
\hline Faturamento em 2014 & R\$ 52.000.000,00 & R\$ 2.000.000,00 & R\$ 8.000.000,00 & R\$ 1.800.000,00 \\
\hline Tipo de Calçados & $\begin{array}{c}\text { Sapatênis Casual } \\
\text { Jogging (esportivo) } \\
\text { Confort Casual } \\
\text { Sandálias/Bota }\end{array}$ & $\begin{array}{c}\text { Sandálias } \\
\text { Sálias Casuais }\end{array}$ & $\begin{array}{c}\text { Tênis } \\
\text { Papete Infantil } \\
\text { Esportivo Casual }\end{array}$ & Bota Adventure (Lifestyle) \\
\hline Prod. de Calçados/Mês & \begin{tabular}{c}
176.000 \\
\hline
\end{tabular} & 17.600 & 22.000 & 11.000 \\
\hline
\end{tabular}

Fonte Dados da Pesquisa 
As empresas foram selecionadas, após as etapas iniciais das pesquisas documentais, consultas em órgãos oficiais e pelo processo de entrevistas focadas, conforme descrito na proposta metodológica. As empresas foram descritas no Quadro 3 com codinomes para preservar o anonimato. As entrevistas nas empresas foram realizadas com os proprietários e tiveram duração média de 2 horas e quatorze minutos.

A seção seguinte contempla a análise dos dados, iniciando-se pela caracterização dos processos de inovação das empresas estudadas para em seguida detalhar a natureza das redes empresariais.

\section{ANÁLISE DOS RESULTADOS}

\subsection{Inovação em Produtos e Processos - Categorias Nucleares Básicas}

Tendo em vista as premissas de Carreteiro (2009), as características comuns de empresas de Alto Desempenho Inovativo apresentam: a) melhorias permanentes nos processos de fabricação e gestão, com introdução de novas tecnologias, valorização de ideias de funcionários, fornecedores e clientes que levem a redução de custos de produção, qualidade nos produtos fabricados e melhoria permanente da gestão da empresa; b) Introdução permanente de novas fontes de matéria prima para aprimorar a qualidade do produto final; c) Realização permanente de pesquisas, formal ou informal, para medir o nível de satisfação dos clientes e ter os resultados como fontes para aprimorar a qualidade do atendimento; d) pensam a inovação de processos como um meio de aumentar faturamento e reduzir seus custos de fabricação e superar a concorrência.

Com relação à inovação em produtos, essas empresas se destacam em: a) Desenvolver produtos e serviços de qualidade que atenda a necessidade do cliente; b) Lançamentos de novos produtos através de pesquisas junto aos consumidores, pesquisa junto ao mercado potencial da empresa, e aferir periodicamente qual é a representatividade da venda desses novos produtos sobre o faturamento bruto da empresa; c) Exportar seus produtos - empresas que exportam estão em contato com mercados globalizados, o que pode ser um bom parâmetro para trazer inovações aos seus produtos; d) Buscam novos mercados todos os anos.

No outro extremo, as empresas caracterizadas como de Baixo Desempenho Inovativo possuem categorias nucleares que as colocam nesta posição e que fazem com que tenham dificuldades em inovar. São categorias comuns desse grupo focal: a) Falta uma clara predisposição para investimentos em aquisição de novas máquinas, realizar parcerias com fornecedores para melhorar o processo produtivo os investimentos que realizam visam antes, manter a produtividade nos níveis atuais; b) Não investem em novas matérias-primas que melhorem o processo produtivo e aumentem a qualidade final do produto; c) Não possuem indicadores para medir desempenho e não contam com sólido processo que visa ao aproveitamento de ideias de funcionários, fornecedores e clientes que elevem o nível de inovação em processos; d) A avaliação dos consumidores e mercado com relação à empresa não é considerada de nível excelente, pois não há uma clara estratégia de investimentos em serviços e produtos de qualidade que as diferenciam no mercado.

Com relação à inovação em produtos, suas categorias nucleares incluem: a) Baixo índice de lançamentos de novos produtos que sejam considerados inovadores; b) Não há uma estratégia clara por parte da empresa na exportação de produtos; c) Mesmo introduzindo melhorias em produtos já existentes o nível de retorno é baixo - essas melhorias são introduzidas em produtos já existentes que já não apresentavam bons níveis de inovação; d) A produtividade geral é baixa - esse fato eleva o custo mensal da empresa por funcionário e reduz ainda mais seu potencial para inovação em produtos.

\subsection{Análise das Redes Empresariais - Análises Comparativas}

Verificou-se pelas análises comparativas realizadas nos dados empíricos que as empresas descritas como de Alto Desempenho Inovativo apresentam características comuns em suas redes de relacionamentos. Tais características incluem forte presença de laços fortes nos relacionamentos internos ao espaço geográfico definido, com reduzida presença de atores isolados, e laços fracos que fazem pontes além territó- 
rio produtivo; rede de relacionamento com conexões em várias regiões e estados da federação; relevante indicação de propagação de informações e recursos sobretudo no interior do território produtivo, no qual possui uma cadeia produtiva ampla e diversificada; fornecedores e clientes extremamente integrados na rede, o que facilita que inovações de fora do território produtivo sejam internalizadas com mais facilidade.

Os cálculos das medidas relacionais de redes indicam que as redes dessas empresas de alto desempenho inovativo (L Calçados Ltda e D Calçados Ltda) apresentam uma Coesão Social e Empresarial mais pronunciada com indicadores de 74,10 e 52,10, respectivamente. Os atores que aparecem com maior Grau de Centralidade, Proximidade e Centralidade de Informação na rede fazem parte da cadeia produtiva, em que as empresas pesquisadas desenvolvem parceria em processos inovadores, fato esse bastante evidenciado nas entrevistas realizadas com os proprietários das empresas pesquisadas.

Quanto às medidas estruturais, foram indicativos nos cálculos, redes mais densas, com a empresa $\mathrm{L}$ Calçados com indicador de 30,8\% e a D Calçados com indicador de $16,01 \%$, e medida de transitividade com proporções mais acentuadas de tríades sob díades, o que favorece transferências de informações e recursos no interior das redes pesquisadas. Dados qualitativos das redes descritas denotam que as empresas pesquisadas apresentam contatos frequentes, caracterizados como de laços fracos, além território produtivo, com fornecedores de máquinas e equipamentos, demonstrando empiricamente as alegações de Lundvall e Nielsen (2007), de que "relacionar as interações entre fabricantes de equipamentos e as inovações a nível de processo, levam consequentemente a inovações ao nível de produção de bens de consumo".

As evidências descritas acima, ainda corroboram os argumentos de Granovetter $(1973,1985,2005)$ e de Rowley et al. (2001), no qual redes com prevalência de laços fortes são canais preferenciais de trânsito de informações e recursos de natureza mais refinada e, ainda Burt (1992) de laços fracos serem pontes para unir atores em redes distantes. As empresas de baixo desempenho inovativo, a exemplo do outro grupo focal, também apresentam redes de relacionamento com relevante concentração no território produtivo de Nova Serrana.
No entanto, apesar das análises demonstrarem a concentração no espaço geográfico definido, a presença significativa de atores isolados intra-polo e mesmo além, com frequência pronunciada de contatos efetivos caracterizados como de laços fracos, mesmo considerando a excelência em categorias dos contatos apresentados, indicam que as redes de relacionamentos dessas empresas não vêm absorvendo de forma mais efetiva as informações e recursos de que necessitam em seu processo de inovação em processos e produtos. Retorna-se aqui em Burt (1992), que enfatiza os argumentos de Eficácia e Eficiência de uma rede de relacionamentos em otimizar a retenção e distribuição de informações e recursos em seu interior. Esse autor sugere o aumento de contatos não redundantes no interior da rede e um foco específico em contatos primários. Diante das análises empreendidas sobre as redes de relacionamentos de empresas de baixo desempenho inovativo, tais características fundamentais, em Burt (1992), lhes faltam.

As análises das medidas relacionais das redes de relacionamento em questão apresentam, na média, indicadores de Coesão Social que denotam a presença relevante de atores isolados e frequência de contatos caracterizados como de laços fracos, P Calçados Ltda. com indicador 19,01 e S Calçados com indicador de 59,02 (essa empresa apresentou esse indicador pelo número reduzido de atores informados na rede). Os indicadores de Grau de Centralidade e Proximidade apresentaram o SINDINOVA (S Calçados Ltda.) e SINDINOVA e Central de Compra, Venda e Logística (P Calçados Ltda.) como atores mais importantes, evidenciando a dependência das empresas de baixo desempenho inovativo às instituições de apoio como meios para seu desenvolvimento.

As medidas de Densidade de Rede refletem os itens discutidos acima. Verifica-se que suas redes têm uma densidade global extremamente baixa. A empresa P Calçados apresenta densidade de 3,78\% e a S Calçados Ltda. densidade de $14,06 \%$, indicando como a troca de informações e recursos de cunho mais refinado na rede está sobremaneira prejudicada. Concluindo, a medida de Transitividade que representa a facilidade da rede em transformar díades em tríades, e assim fomentar transferência de informações e recursos em seu interior, apresentam indicadores de 1/0,193 e 1/0,278 para as empresas $\mathrm{P}$ 
Calçados Ltda. e S Calçados Ltda., respectivamente. Esse item em específico vem a corroborar as análises empreendidas, indicando a dificuldade que as redes apresentam de criar mecanismos de transferência de recursos e informações em seu interior. A Tabela 1 demonstra as medidas relacionais e estruturais das redes pesquisadas.

Tabela 1 Natureza das redes das empresas pesquisadas por desempenho inovativo

\begin{tabular}{|c|c|c|c|c|}
\hline \multirow{2}{*}{$\frac{\text { Categorias }}{\text { Medidas Relacionais }}$} & \multicolumn{2}{|c|}{ Empresas de Alto Desempenho } & \multicolumn{2}{|c|}{ Empresas de Baixo Desempenho } \\
\hline & L Calçados & D Calçados & P Calçados & S Calçados \\
\hline Grau de Centralidade & Croc Calçados & Ac Calçados & SINDINOVA & SINDINOVA \\
\hline Coesão Social & 74,10 & 52,10 & 19,01 & 59,02 \\
\hline Proximidade & $\begin{array}{l}\text { Alan Calçados } \\
\text { Ranvale } \\
\text { Croc Calçados }\end{array}$ & Ac Calçados & $\begin{array}{l}\text { SINDINOVA } \\
\text { Central de Compra, } \\
\text { Venda e Logística }\end{array}$ & SINDINOVA \\
\hline $\begin{array}{l}\text { Centralidade } \\
\text { de Informação }\end{array}$ & Renvale Calçados & Ac Calçados & Não há & Não há \\
\hline Medidas Estruturais & L Calçados & D Calçados & P Calçados & S Calçados \\
\hline Densidade da Rede & $30,83 \%$ & $16,01 \%$ & $3,87 \%$ & $14,55 \%$ \\
\hline Transitividade & $1 / 0,0623$ & $1 / 0,380$ & $1 / 0,193$ & $1 / 0,278$ \\
\hline
\end{tabular}

Fonte Dados da pesquisa.

As Figuras de números 4 a 7 representam o território calçadista de Nova Serrana (delimitado pelas linhas tracejadas), e comparadas pelas suas características de terem um maior ou menor desempenho inovativo, tendo em vista os critérios definidos nos objetivos da pesquisa.

Na Figura 4, verifica-se a distribuição geográfica da rede de cada empresa pesquisada, demonstrando a sua interconexão tanto dentro como além do território. As empresas de baixo desempenho inovativo apresentam-se mais concentradas dentro do território produtivo.

$\mathrm{Na}$ Figura 4, as cores representam os locais que as empresas estão localizadas, sendo que o quadrado pontilhado representa os limites do polo calçadista de Nova Serrana (MG). Todas as empresas que estão dentro do polo estão em representadas pela cor amarela e as empresas fora do polo estão designadas pelas seguintes cores: verde para Belo Horizonte (MG), azul para São Paulo (SP), preto para Rio Grande do Sul (RS), rosa para Espírito Santo (ES) e laranja para Distrito Federal (DF). Os números são indicativos das empresas cujos nomes foram omitidos por questões de sigilo.

A Figura 5 compara as categorias dos contatos registrados entre os dois grupos pesquisados. Foi adotada a mesma notação da Figura 4, usando o quadrado pontilhado para delimitar as fronteiras do polo calçadista. Já para os tipos de contatos, foi adotada uma nova categorização, conforme as seguintes cores: rosa para a Central de Exportação, azul para a Central de Vendas, preto para a Central de Compras, roxo para as ONGs (Organizações Não-Governamentais), laranja para a FIEMG (Federação das Indústrias do Estado de Minas Gerais), amarelo para o Sindicato das Empresas Calçadistas, branco para os fornecedores, vermelho para os clientes, marrom para outras empresas calçadistas do polo de Nova Serrana e cinza para contatos pessoais. Verifica-se que as empresas de maior desempenho inovativo apresentam poucos atores isolados em suas redes e uma gama mais considerável de atores diversificados. A diversificação evidencia uma participação maior desse grupo dentro da cadeia de fabricação de calçados. 
Figura 4 Comparativo - distribuição geográfica

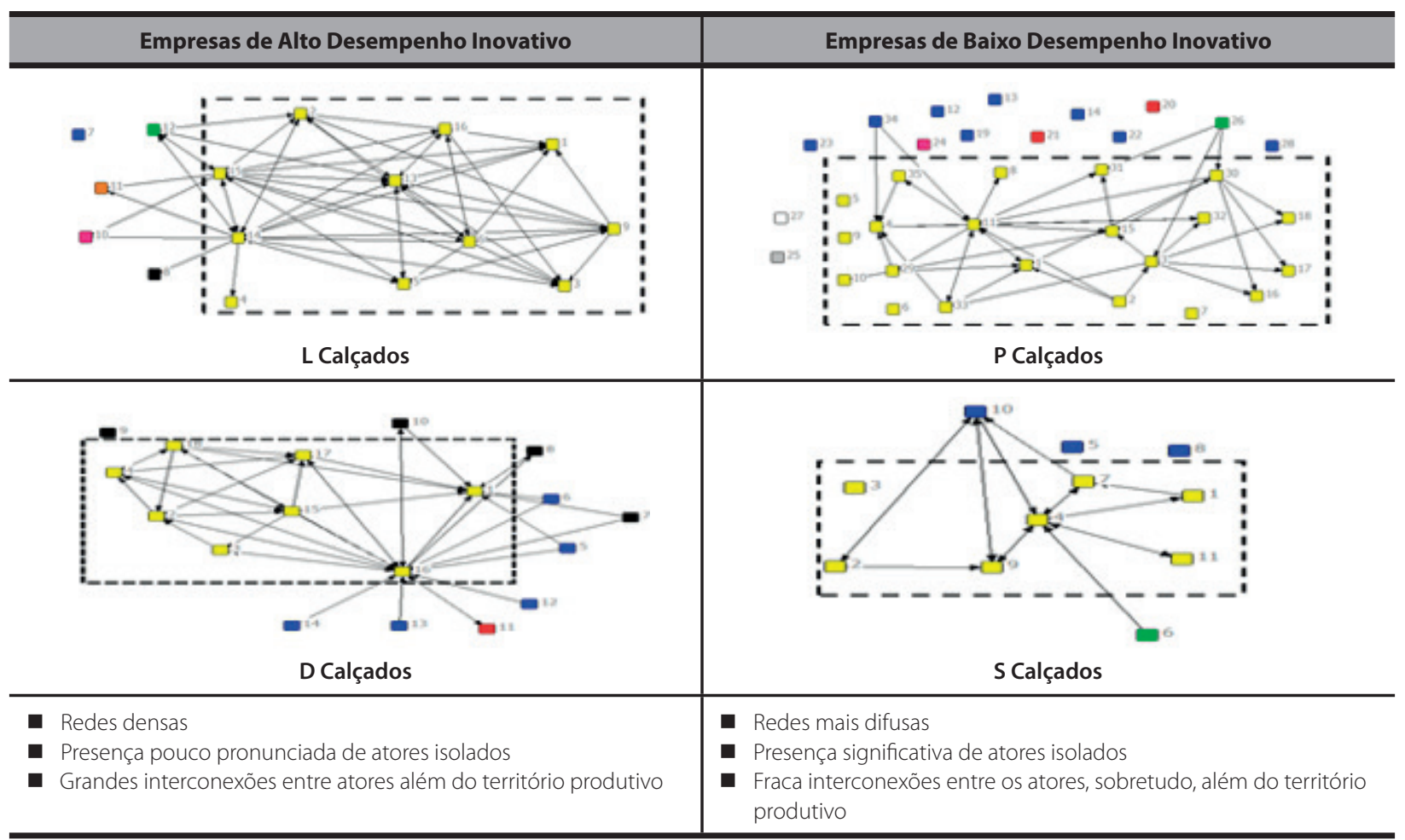

Fonte Elaborado pelos autores

Figura 5 Comparativo - categorias de contatos

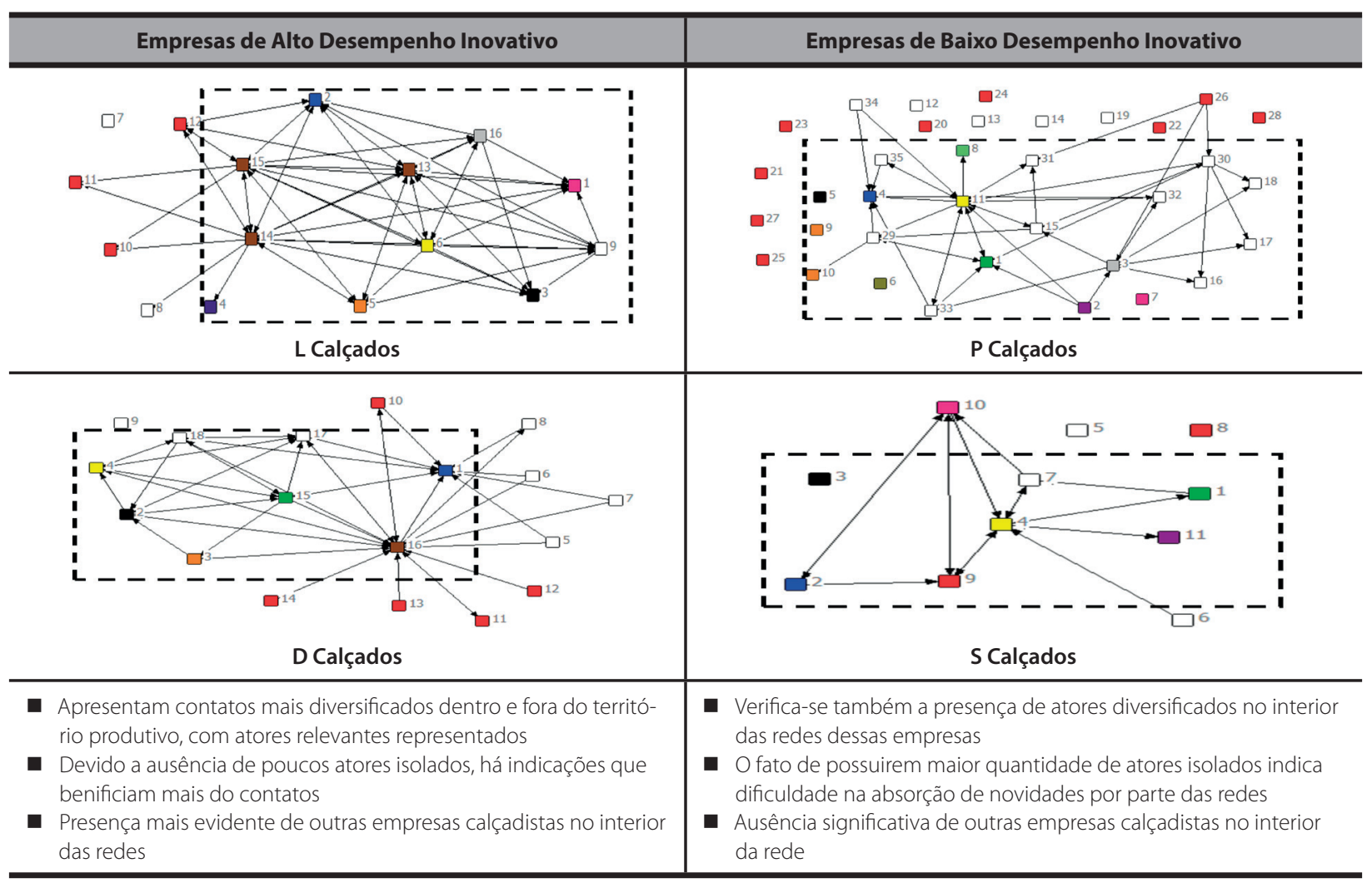

Fonte Elaborado pelos autores 
Figura 6 Comparativo - frequência de contatos

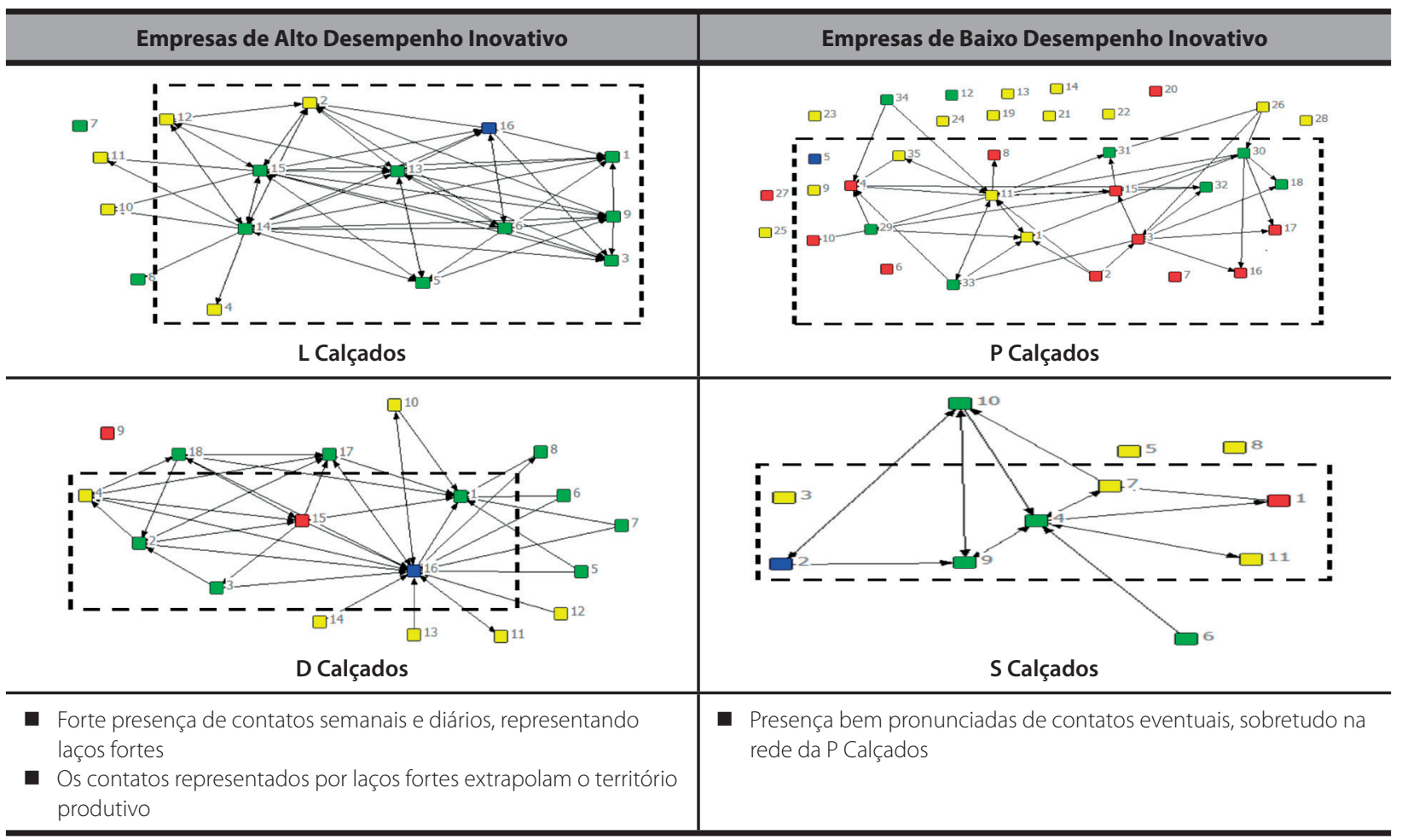

Fonte Elaborado pelos autores

Figura 7 Comparativo - propagação de informações e recursos

\begin{tabular}{|c|c|}
\hline Empresas de Alto Desempenho Inovativo & Empresas de Baixo Desempenho Inovativo \\
\hline 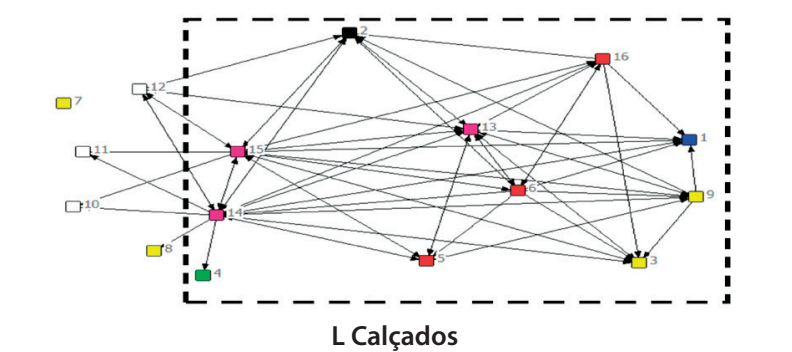 & P Calçados \\
\hline D Calçados & SCalçados \\
\hline $\begin{array}{l}\text { - Forte propagação de informações e recursos no interior do territó- } \\
\text { rio produtivo } \\
\text { - Fornecedores e clientes mais integrados nas redes } \\
\text { - Devido uma forte conexão entre os autores, além território produ- } \\
\text { tivo, verifica-se maior propagação de informações e recursos }\end{array}$ & $\begin{array}{l}\text { - Maior propagação de informações e recursos dentro do território } \\
\text { produtivo } \\
\text { - Maior presença de atores isolados, dificulta a propagação de infor- } \\
\text { mações e recursos para dentro do território produtivo e vice-versa } \\
\text { - A S Calçados apresenta uma rede com baixo nivel de propagação } \\
\text { de informações e recursos, devido ao número limitado de atores } \\
\text { na rede }\end{array}$ \\
\hline
\end{tabular}

Fonte Elaborado pelos autores 
A Figura 6 apresenta a frequência de contatos. Novamente, é mantida a notação do quadrado pontilhado para os limites do polo. A notação das cores obedece a seguinte classificação conforme a periodicidade dos contatos: azul para contatos diários, verde para contatos semanais, amarelo para contatos mensais e vermelho para contatos eventuais. A baixa frequência dos contatos é bem pronunciada nas empresas de baixo desempenho inovativo. Essa característica é essencial na determinação do nível de inovação que uma empresa apresenta, tendo em vista que a frequência dos contatos facilita que recursos vitais sejam transferidos pelos atores através de suas interconexões em rede.

A Figura 7 apresenta a propagação de informações e recursos dentro das redes pesquisadas. A notação das cores diferencia os seguintes tipos de informações: azul para informações sobre eventos locais, vermelho para informações oriundas de consultoria, amarelo para dados sobre compra de Insumos, branco para dados sobre venda de produtos, verde escuro para informações sobre serviços bancários, cinza para informações sobre clube de serviços e recreação, roxo para informações políticas, verde claro para informações sobre responsabilidade social e por fim, preto para informações sobre preços e mercados Importadores. Verifica-se que empresas de maior desempenho inovativo apresentam uma maior fluidez nas informações, o que pode favorecer uma maior absorção de recursos vitais para eleva-las à categoria de empresas mais inovadoras. Esse dado torna-se relevante, também, em facilitar uma maior integração da rede, desenvolvendo as interconexões descritas como "laços fortes", vitais para o trâmite de informações mais refinadas.

A próxima seção sumariza os resultados obtidos, discute as limitações da pesquisa e apresenta sugestões para trabalhos futuros.

\section{CONCLUSÕES}

Por meio das análises empreendidas pode-se concluir que as empresas tidas como de alto desempenho inovativo conseguem captar de maneira mais dinâmica informações e recursos que trafegam em suas redes de relacionamento, apresentando as seguintes características nucleares: a) são empresas que implementam melhorias continuas em processo e produtos, com introdução permanente de novas tecnologias, b) apresentam processos parar captar e tratar novas ideias de funcionários, fornecedores e clientes, c) são empresas que têm uma preocupação central com a qualidade dos produtos fabricados, d) essas empresas pensam a inovação de processos e produtos como um meio de vencer a concorrência, se perpetuar e gerar resultados satisfatórios para seus proprietários, funcionários e a sociedade em geral. Essas empresas, conforme alega Burt (1992), apresentam redes de relacionamento mais otimizadas nas quais existe um aproveitamento mais dinâmico dos contatos primários e contatos não redundantes.

As análises gráficas, juntamente com as medidas de redes estruturais e relacionais e os dados qualitativos da pesquisa, indicam que as redes dessas empresas são mais aptas em propagar informações e recursos que são usados para fomentar processos inovativos no interior dessas firmas. As características inovadoras chamadas de nucleares irradiam para todas as atividades da empresa, conforme descritos, e são fatores que induzem o sucesso, e assim fomentam processos inovativos em cadeia no interior dessas firmas. Em estudo recente sobre a inovação do polo calçadista do Rio Grande do Sul, Gewehr (2018) analisou como a estratégia ofensiva de inovação de uma empresa fornecedora de insumos têxteis promovia a inovação no polo calçadista. $\mathrm{O}$ estudo conclui que a inovação no setor de calçados é usualmente ditada pela tecnologia de fornecedores e nos materiais utilizados (componentes).

No entanto, apesar de indicar diferenças nas redes de relacionamento das empresas de alto e baixo desempenho inovativo, este estudo apresenta limitações, uma vez que não abordou o universo relacional mais amplo possível das empresas pesquisadas, a quantidade de casos pesquisados e ainda por representar um setor econômico específico. Conforme ressaltam Turkina e Assche (2018), estudos sobre clusters apresentam limitações inerentes, pois não há evidências da possibilidade de uma abordagem única do tipo one size fits all para recomendar como as conexões de um arranjo devem ser construídas de maneira otimizada.

Novas pesquisas com amostras mais significativas e focando em pontos específicos identificados 
poderão trazer contribuições de como as empresas poderão atuar ampliando suas redes de relacionamentos, interconectando com mais acuidade atores isolados nessas redes e apontando se os recursos internos às empresas, tais como nível de escolaridade de seus proprietários e funcionários, sistemas operacionais utilizados, nível de remuneração apresentada, são fatores essenciais para criar e manter redes de relacionamentos e, em última instância, facilitar a absorção de informações e recursos por parte da firma e assim fomentar com mais eficiência processos inovativos em seu interior. Adicionalmente, recomenda-se como trabalho futuro o desenvolvimento de um estudo de natureza longitudinal do polo calçadista, pois Boschma (2015) destaca a importância de analisar a trajetória histórica de um cluster, pois seu passado histórico tanto pode limitar a sua capacidade de renovação quanto estipular novas oportunidades.

Entende-se que o artigo contribui para o entendimento de como as diversas configurações de redes de relacionamentos são aptas em transitar com informações e recursos no seu interior. Estudos sobre territórios produtivos são relevantes, pois Turkina e Assche (2018) ressaltam que, na economia do conhecimento, clusters são direcionadores fundamentais da competitividade dos países. $\mathrm{O}$ artigo busca ampliar a compreensão sobre o tema no sentido de fazer um estudo comparativo de duas categorias distintas de empresas no contexto de um espaço geográfico dinâmico e também em apresentar configurações de redes sociais e empresariais que são mais aptas em propagar informações e recursos em seu interior.

\section{REFERÊNCIAS}

AHUJA, G. Collaboration networks, structural holes, and innovation: a longitudinal study. Administrative Science Quarterly, v.45, n.3, p. 425-455, 2000.

AMATO NETO, J. Redes de Cooperação Produtiva e Clusters Regionais - Oportunidades para as Pequenas e Médias Empresas. São Paulo: Atlas, 2000.

BALESTRIN, A. \& VERSCHOORE, J. Redes de cooperação empresarial: estratégias de gestão na nova economia. Porto Alegre: Bookman, 2008.
BITTENCOURT, B. A.; GALUK, M. B.; DANIEL, V. M.; ZEN, A. C. Cluster Innovation Capability: A Systematic Review. International Journal of Innovation, v. 7, n. 1, p. 26-44, 2019.

BOSCHMA, R. A. Towards an evolutionary perspective on regional resilience. Papers in Evolutionary Economic Geography, V. 9, p. 1-27, 2015.

BRAGA, F. \& FAZITO, D. Análise de redes sociais e as conexões territoriais da migração no Brasil. Belo Horizonte: Cedeplar, 2011.

BRITTO, J., STALLIVIERI, F., CAMPOS, R. \& VARGAS, M. Padrões de aprendizagem, cooperação e inovação em aglomerações produtivas no Brasil: uma análise multivariada exploratória. Anais do 35 Encontro Nacional de Economia da ANPEC, RJ, 2007.

BURT. S. Structural holes: the social structure of competition. Cambridge: Harvard University Press, 1992.

CANONGIA, C., SANTOS, D. M., SANTOS, M. M. \& Z. ACKIEWICZ, M. Foresight, Inteligência competitiva e gestão do conhecimento: instrumentos para a gestão da inovação. Gestão \& Produção, v. 11, n.2, p. 231-238, 2004.

CAPIOTO, G. R., BARBOSA, D. H., KURUMOTO, J. S., \& COTRIM, S. L. Suppliers' network analysis under the perspective of structural, relational and cognitive embeddedness: an exploratory study. Production, 29, e20180041, 2019.

CARRETEIRO, R. Inovação tecnológica. Rio de Janeiro: LTC, 2009.

CASTILLA, E. J., HWANG, H., GRANOVETTER, E. \& GRANOVETTER, M. Social networks in Silicon Valley. In: C.-M. Lee, W. F. Miller, M. G. Hancock \& H. Rowen (Ed.). The Silicon Valley Edge, v.11, p. 218-408. Stanford: Stanford University Press, 2000. 
CHESBROUGH, H. W. Open innovation: the new imperative for creating and profiting from technology, Boston: Harvard Business School Press, 2003.

CROCCO, M., SANTOS, F., SIMÕES, R. \& HORÁCIO, F. Industrialização descentralizada: sistemas industriais locais: o arranjo produtivo calçadista de Nova Serrana. Parcerias Estratégicas, v. 8, n. 17, p. 55-133, 2001.

DAVILA, T., EPSTEIN, M. \& SHELTON, R. As regras da inovação. Porto Alegre: Bookman, 2007.

EISENHARDT, K. M. Building theories from case study research. Academy of Management Review, v. 14 , n. 4 , p. 532-550, 1989.

EVERETT, M. \& BORGATTI, S. UCINET VI. Massachussetts: Analytical Technology, 2000.

FIALHO, J. R. Análise de redes sociais: princípios, linguagem e estratégias de ação na gestão do conhecimento. Perspectivas em Gestão e Conhecimento, v. 4, p. 9-26, 2014.

GEWEHR, A. C. Estratégia de Inovação no 'Cluster' Calçadista do Estado do Rio Grande do Sul . Revista Economia \& Gestão, v. 18, n. 51, p. 45-61, 2018.

GIL, A. C. Métodos e técnicas de pesquisa social. São Paulo: Atlas, 2008.

GOLLO, S. S. Framework para análise das inovações e das estratégias de cooperação competitiva - coopetição. Anais do $30^{\circ}$ Encontro da ANPAD, Salvador, 2006.

GÓMES, D., GONZALEZ-ARANGUENA, E., MANUEL, C., OWEN, G., POZO, M. \& TEJADA, J. Centrality and power in social network: a game theoretic approach. Mathematical Social Sciences, v. 46, n. 1, p. 27-54, 2003.

GRANOVETTER, M. The strength of weak ties. The American Journal of Sociology, v. 78, n.6, p. 13601380, 1973.
GRANOVETTER, M. Network Sampling: Some First Steps. The American Journal of Sociology, v. 81, n.6, p. 1287-1303, 1973.

GRANOVETTER, M. Economic action and social structure: the problem of embeddedness. The American Journal of Sociology, v. 91, n. 3, p. 481510, 1985.

GRANOVETTER, M. The Impact of social structure on economic outcomes. Journal of Economics Perspectives, v. 19, n. 1, p. 33-50, 2005.

GRANOVETTER, M. Ação econômica e estrutura social: o problema da imersão. Revista de Administração de Empresas Eletrônica, v. 6, n.1, 2007.

HALINEN, A. \&TORNROOS, J.-A. The role of embeddedness in the evolution of business networks. Scandinavian Journal of Management, v.14, n. 3, p. 187-205, 1998.

INSTITUTO BRASILEIRO DE GEOGRAFIA E ESTATÍSTICA. Produto interno bruto dos municípios: 2004 a 2008. Rio de Janeiro: IBGE. Recuperado em 26 jan. 2015 de: www.ibge.gov.br/home/estatística/economia/pibmunicipios/2004_2008/, 2010.

LAZEGA, E. \& HIGGINS, S. S. Redes sociais e estruturas relacionais. Belo Horizonte: Fino Traço.

LEMIEUX, V. \& OUIMET, M. Análise estrutural das redes sociais. Lisboa: Instituto Piaget, 2012.

LEMOS, A. P. Repercussões dos Turnover na Indústria Calçadista de Nova Serrana. Dissertação de Mestrado, Faculdades Integradas de Pedro Leopoldo, MG, Brasil, 2009.

LEONARD-BARTON, D. A dual methodology for case studies. Organization Science, v.1, n. 3, p. 248266, 1990. 
LI, P.-F., BATHELT, H. \& WANG, J. Network dynamics and cluster evolution: changing trajectories of the aluminium extrusion industry in Dali, China. Journal of Economic Geography, v. 12, n. 1, p. 127155, 2011.

LUNDVALL, B. A. \& NIELSEN, P. Knowledge management and innovation performance. International Journal of Manpower, v. 28, n. 3/4, p. 207-223, 2007.

MACIEL, C. O. \& CASTRO, M. Configurações reticulares e inovação. Revista Brasileira de Estratégia, v. 3, n. 1, p. 71-85, 2010.

MARTES, A. C. B.; BULGACOV, S.; NASCIMENTO, M. R.; GONÇALVES, S. A.; AUGUSTO, P. M. Fórum - Redes Sociais e Interorganizacionais. Revista de Administração Eletrônica, v. 46, n. 3, p. 10-15, 2006.

MARSHALL, A. Princípios de economia: tratado introdutório. São Paulo: Abril, 1982.

MELO FILHO, L. D. R.; GONÇALVES, C. A.; CHENG, L. C.; MUNIZ, R. M. Abordagem Estratégica de Roadmapping na Geração de Diretrizes de Inovação para Firmas de um Conglomerado Industrial. Revista Ibero-Americana de Estratégia, v. 14, n. 3, p. 49-74, 2015.

MEYER, C. B. A case in case study methodology. Field Methods, v.13, n.4, 329-352, 2001.

MIZRUCHI, M. S. Análise de redes sociais: avanços recentes e controvérsias atuais. Revista de Administração de Empresas, v. 46, n. 3, 72-86, 2006.

MONDINI, V. E. D.; AMAL, M.; GOMES, G. Influência dos Recursos do Cluster no Desempenho Inovador de Empresas Têxteis. BASE - Revista de Administração e Contabilidade da UNISINOS, v. 13, n. 4, p. 279-293, 2016.

MULLER, E. The efficient governance of clusters: an analysis of different modes of cluster management. Conference School of Economics and Business, Bósnia, 2009.
PELLEGRIN, I., BALESTRO, M. V.; ANTUNES JUNIOR, J. \& CAULLIRAUX, H. M. Redes de inovação: construção e gestão da cooperação pró-inovação. Revista de Administração, v. 42, n. 3, p. 313-325, 2007.

POWELL, W. W., KOPUT, K. W. \& SMITH-DOERR, L. Interorganizational collaboration and the locus of innovation: networks of learning in biotechnology. Administrative Science Quarterly, v. 41, n. 1, p. 116-145, 1996.

RASERA, M.; BALBINOT, Z. Redes de inovação, inovação em redes e inovação aberta. Análise - Revista Acadêmica da Face, v. 21, n. 2, p. 127-136, 2010.

RESENDE, P. T. V. A viabilidade operacional do cluster calçadista de Nova Serrana. Revista Internacional de Desenvolvimento Local, v. 5, n. 8, p. 45-53, 2004.

ROBERTSON, P. L., CASALI, G. L. \& JACOBSON, D. Managing open incremental process innovation. Research Policy, v. 41, n. 5, p. 822-832, 2012.

ROWLEY, T., BEHRENS, D. \&KRACKHARDT, D. Redundant governance structures: an analysis of structural and relational embeddedness in the steel and semiconductor industries. Strategic Management Journal, v. 21, n. 3, p. 369-386, 2000.

SACOMANO NETO, M. Morfologia, propriedades e posicionamentos das redes: contribuições às análises das firmas. Anais do $11^{\circ}$ SIMPEP, Bauru, SP, 2004.

SACOMANO NETO, M.; TRUZZI, O. M. S. Configurações estruturais e relacionais da rede de fornecedores. Revista de Administração, v. 39, n.3, p. 255-263, 2004.

SANTOS, H. N. Uma experiência em design de produto em uma indústria calçadista de Nova Serrana - MG. Dissertação de Mestrado, Escola de Engenharia da Universidade Federal de Minas Gerais, Belo Horizonte, MG, Brasil, 2009.

SCHUMPETER, J. A. Teoria do desenvolvimento econômico. São Paulo: Abril, 1982. 
SCHMIDT, V. K.; ZEN, A. C. Desenvolvimento Regional e Resiliência de Cluster: Uma Proposta Teórica . Revista Pensamento Contemporâneo em Administração, v. 13, n. 1, p. 31-45, 2019.

SUZIGAN, W., FURTADO, J., GARCIA, R. \& SAMPAIO, S. E. K. A indústria de calçados de Nova Serrana (MG). Nova Economia, v. 15, n. 3, p. 97116, 2005.

TEDESCO, J. C. Georg Simmel e as ambiguidades da modernidade. Ciências Sociais, Unisinos, v. 43, n. 1, 56-67, 2007.

TIDD, J., BESSANT, J. \& PAVITT, K. Gestão da Inovação. Porto Alegre. Bookman, 2008.

TOMAÉL, M. I. \& MARTELETO, R. M. Redes sociais: posições dos atores no fluxo da informação. Revista Eletrônica de Biblioteconomia e Ciência da Informação, (n. esp.), p. 75-91, 2006.

TOMAÉL, M. I., ALCARÁ, A. R. \& DI CHIARA, I. G. Das redes sociais à inovação. Ciência da Informação, v. 34, n. 2, p. 93-104, 2005.

TURKINA, E.; ASSCHE, A.V. Global connectedness and local innovation in industrial clusters. Journal of International Business Studies, v. 49, p. 706-728, 2018.

VALE, G. M. V. \& CASTRO, J. M. Clusters, arranjos produtivos locais, distritos industriais: reflexões sobre aglomerados produtivos. Análise Econômica, v. 28, n. 53, 81-97, 2010.

VALE, G. M. V. Laços como ativos territoriais. Revista de Desenvolvimento Econômico, v. 8, n. 14, p. 3442, 2006.

VALE, G. M. V. Territórios vitoriosos: o papel das redes organizacionais. Rio de Janeiro: Garamond, 2007.

VASCONCELOS, M. R. \& OLIVEIRA, J. L. Imersão social e institucional e capacidades: o setor calçadista de Nova Serrana. RAE, v. 52, n. 5, p. 531-545, 2012.
WASSERMAN, S. \& FAUST, K. Social network analysis: methods and applications: structural analysis in the social sciences. Cambridge: Cambridge University Press, 1994.

YIN, R. K. Estudo de caso: planejamento e métodos. São Paulo: Bookman, 2010. 